\title{
Educação Patrimonial e ações educativas do Projeto “Arqueólogo por um dia: história e natureza”
}

\author{
Heritage Education and educational actions of the Project \\ "Archaeologist for a day: history and nature" \\ Neli Teresinha Galarce Machado* \\ Sérgio Nunes Lopes ${ }^{* *}$ \\ Patrícia Schneider ${ }^{* * *}$ \\ Lucas Fernando Schneider ${ }^{* * * *}$ \\ Lara Isadora Pereira ${ }^{* * * *}$
}

Palavras-chave:
Educação Patrimonial
Extensão Universitária
Curricularização da Extensão

Keywords:

Educacion in Heritage

University Extension

Curricular Extension

\begin{abstract}
Resumo: A extensão universitária trilha novos caminhos e se fortalece enquanto campo de ação que relaciona o espaço acadêmico e as comunidades. O projeto de extensão "Arqueólogo por um dia: história e natureza" tem como fundamento a difusão do conhecimento científico sobre a história regional, por meio da Educação Patrimonial. O artigo discute a concepção de Educação Patrimonial, de extensão universitária e de curricularização da extensão. Tais reflexões apresentam os dados produzidos pelas experiências extensionistas vivenciadas e a normatização legislativa recentemente implementada e dirigida às instituições de Ensino Superior como desdobramentos do Plano Nacional de Educação. Nesta pesquisa, são informados dados quantitativos relativos ao número de estudantes do Ensino Básico atendidos pelo projeto desde o início das atividades. As discussões conceituais sobre os dados da pesquisa são tratadas didaticamente a fim de desencadear situações pedagogicamente potentes no que concerne à Educação Patrimonial.
\end{abstract}

Abstract: The university extension traces new paths and strengthens itself as a field of action that relates academic space and communities. The extension project "Archaeologist for a day: history and nature" has as the basis the dissemination of scientific knowledge on regional history, through Heritage Education. The article discusses the conception of Education in Heritage, university extension and curricular extension. These reflections present the data produced by extensionist experiences and the legislative regulation recently implemented and addressed to higher education institutions as a result of the National Education Plan. In this research, quantitative data are reported the number of students attending the project since the beginning of the activities. The conceptual discussions about the data of research are dealt didactially in order to trigger pedagogically potent situations in what concerns Heritage Education.

Recebido em 31 de maio de 2019. Aprovado em 28 de agosto de 2019.

\footnotetext{
* Doutora em Arqueologia pela Universidade de São Paulo (USP). Professora da Universidade do Vale do Taquari (Univates). Coordenadora do Laboratório de Arqueologia e do Programa de Pós-Graduação em Ambiente e Desenvolvimento (PPGAD) da Univates). ORCID: https://orcid. org/0000-0003-1209-5353.E-mail:<ngalarce@univates.br>.

** Mestre em Patrimônio Cultural pela Universidade Federal de Santa Maria (UFSM). Professor da Universidade do Vale do Taquari (Univates) e da Rede Municipal de Arroio do Meio/RS. Professor extensionista do projeto "Arqueólogo por um dia: História e Natureza". ORCID: https://orcid. org/0000-0002-7421-0284. E-mail: <sergionl77@univates.br>.

*** Mestra em Patrimônio Cultural pela Universidade Federal de Santa Maria (UFSM). Supervisora do Centro de Memória, Documentação e Pesquisa do Museu de Ciências da Univates (CMDPU/MCN/Univates). Pesquisadora voluntária do Projeto de Extensão "Arqueólogo por um dia: História e Natureza”. E-mail: <pcissas@univates.br>.

**** Acadêmico do Curso de História (Licenciatura) na Universidade do Vale do Taquari (Univates). Bolsista de Extensão do Projeto "Arqueólogo por um dia: História e Natureza”. E-mail: <lfschneider@universo.univates.br>.

${ }_{* * * * \star}$ Acadêmica do Curso de Relações Internacionais na Universidade do Vale do Taquari (Univates). Bolsista de Extensão do Projeto Arqueólogo por um dia: História e Natureza. E-mail: <lara.pereira@univates.br>.
} 


\section{Introdução}

O projeto de extensão universitária "Arqueólogo por um dia: história e natureza" tem como premissa a Educação Patrimonial. Entre as oportunidades vislumbráveis na divulgação do campo patrimonial, estão a possibilidade de projetos e ações didático-pedagógicas em contextos de educação formal e não formal.

O conjunto de atividades do projeto tem a intenção de sensibilizar estudantes de Ensino Fundamental, Séries Finais e de Ensino Médio para as pesquisas e práticas arqueológicas, como as técnicas do trabalho em campo e as evidências arqueológicas. $\mathrm{O}$ contexto ambiental e o regional completam o circuito dessa vinculação. As abordagens estabelecem conexões com os conteúdos mobilizados nas matrizes curriculares da Educação Básica. No Ensino Fundamental e no Ensino Médio, os currículos, geralmente, preconizam o desenvolvimento de competências e habilidades em relação ao entendimento da inserção humana nas dinâmicas de cada contexto socioambiental. As atividades, portanto, instigam conhecimentos transdisciplinares em áreas como História, Geografia e Ciências.

Para além das temáticas abordadas no projeto, ressalta-se a continuidade das ações e o impacto no desenvolvimento sociocultural das comunidades. No caso específico deste projeto, tem-se a divulgação do conhecimento científico produzido pelas pesquisas arqueológicas, a partir das atividades propostas e protagonizadas pelos acadêmicos extensionistas, com a participação ativa do público-alvo. Esta interação e a troca são os principais processos para o reconhecimento do espaço que estudantes e comunidade ocupam na ação de conhecer e preservar os "patrimônios" já identificados.

Ao longo dos 16 anos de vigência do projeto, estabeleceu-se uma rede de professores das séries finais do Ensino Fundamental e Ensino Médio que incluem as atividades em seu planejamento anual. Acadêmicos dos cursos de graduação em História e Ciências Biológicas da Universidade do Vale do Taquari (Univates), testemunham que, quando estudantes da Educação Básica, participaram das oficinas propiciadas pelo projeto, de certa forma, isso influenciou em suas escolhas profissionais.

Isso posto, em que pese o "nome fantasia" do projeto enunciar "por um dia", a relação estreita com as escolas e o diálogo constante com os professores oportuniza aos envolvidos vivências didático-pedagógicas elementares para a formação profissional. Esses dados convergem para a vinculação duradoura do projeto com o contexto impactado por suas ações.

É importante destacar que o nome "por um dia" está relacionado à realização da escavação "simulada", ponto alto do projeto, a ser executada em um dia na escola. As atividades, porém, principiam com o envio de material explicativo de cada segmento do conjunto de ações para a escola. $\mathrm{O}$ planejamento e a execução das atividades são mediados pelos bolsistas de extensão juntamente com os professores que requisitam a intervenção do projeto em suas práticas pedagógicas.

A estreita relação com as escolas proporciona um intercâmbio constante de saberes. Os acadêmicos e bolsistas são estimulados a perceberem as escolas parceiras como ambiente de coformação. Fazse necessário considerar a potencialidade do conjunto de atividades oferecidas no sentido de responder ao que preconiza o Plano Nacional de Educação quanto à curricularização da extensão. Tais potencialidades verificam-se na participação efetiva dos bolsistas extensionistas nas etapas previstas no projeto, que envolvem a organização prévia junto à escola, a "escavação" precedida de oficina, concluindo-se a solicitação da elaboração de um relatório no qual os estudantes e professores da Educação Básica sugerem aprimoramentos que possibilitam a constante atualização da ação também da perspectiva pedagógica.

Tem-se, dessa forma, momentos qualificados de reflexão em sala de aula, com relação à preservação do Patrimônio Histórico e Cultural, a partir da concepção que esse conjunto de elementos enseja a promoção da cidadania. No que concerne aos aspectos pedagógicos, intenciona-se oferecer alternativas para abordagens menos eurocêntricas, no âmbito das Ciências Humanas e Ambientais, e 
mais interdisciplinares na medida em que as ações concebem o elemento humano como parte dos espaços.

\section{Patrimônio "S"}

O projeto possui por princípio a utilização do ou dos patrimônios como fio condutor de suas ações. O próprio Instituto do Patrimônio Histórico e Artístico Nacional (IPHAN), por meio das portarias ministeriais concedidas aos arqueólogos, solicita e estimula a divulgação dos resultados das investigações científicas, na forma de ações como o que se apresenta como objeto deste artigo. A extensão está estreitamente vinculada à pesquisa científica, esta que, para o desenvolvimento de suas atividades, necessita de autorização daquela autarquia (do IPHAN). O projeto atende à legislação que prevê ações de Educação Patrimonial.

Este projeto pode ser visto como a contrapartida da Instituição de Ensino Superior no que se relaciona à utilização e divulgação do conhecimento científico no âmbito das ações educativas e culturais da Portaria $n^{\circ}$ 07/88 e abrange a Política de Patrimônio Cultural preconizada pela Portaria no 375/2018 (IPHAN, 1988, 2018).

Assim, julga-se conveniente apresentar os conceitos que norteiam as reflexões na presente produção. Conforme o IPHAN, no Decreto $n^{\circ}$ 25 , de 30 de novembro de 1937, entende-se por Patrimônio "[...] o conjunto de bens móveis e imóveis existentes no País e cuja conservação seja de interesse público, quer por sua vinculação a fatos memoráveis da história do Brasil, quer por seu excepcional valor arqueológico ou etnográfico, bibliográfico ou artístico" (IPHAN, 1937).

O Decreto $n^{\circ} 25$ é um marco na legislação brasileira, no que se refere às definições e aos entendimentos sobre o patrimônio; afinal, a partir dele, se explicitou uma moldura acerca da proteção ao Patrimônio Histórico e Artístico Nacional. Doravante, inclusive as constituições que vigoraram no país detiveram-se com mais demora sobre o tema do que as Cartas Magnas precedentes. Contemporaneamente, o art. 216 da Constituição vigente desde 1988 conceitua o Patrimônio Cultural

como os bens " $[. .$.$] de natureza material e imaterial,$ tomados individualmente ou em conjunto, portadores de referência à identidade, à ação, à memória dos diferentes grupos formadores da sociedade brasileira" (BRASIL, 1988).

A conceituação jurídica pressupõe acautelamento, medidas pragmáticas com a intenção, entre outras, de salvaguardar os bens culturais em risco iminente. Riscos estes tangentes à integridade física ou, ainda, às responsabilidades de proteção no âmbito das esferas da administração pública. Potencializar pedagogicamente o Patrimônio Histórico e Cultural, entretanto, demanda reflexões estruturadas a partir do campo epistêmico das Ciências Humanas e Sociais e da Educação.

Como em todos os exercícios no âmbito acadêmico e pedagógico, faz-se necessário eleger as definições conceituais a partir das quais se fundamentam os discursos. Na presente produção, o conceito de Patrimônio Histórico tem como foco as reflexões de Lemos (2006), que o divide em três grupos.

O primeiro grupo seria o natural, o qual inclui os rios e todos os elementos naturais que permitem as mais variadas formas de vida, inclusive a humana.

Nesta categoria estão, por exemplo, os
rios, a água desses rios, os seus peixes,
a carne desses peixes, as suas cachoeiras
e corredeiras transformáveis em força
motriz movendo rodas de moendas,
acionando monjolos e fazendo girar
incrivelmente rápidas as turbinas das
usinas de eletricidade. (LEMOS, 2006,
p. 10).

O segundo grupo refere-se à cognição, ao saber e ao saber fazer.

São os elementos não tangíveis do Patrimônio Cultural. Compreende toda a capacidade de sobrevivência do homem no seu meio ambiente. Vai desde a perícia no rastejamento de uma caça esquiva na floresta escura até as mais altas elucubrações matemáticas apoiadas nos computadores de última geração, que dirigem no espaço cósmico as naves interplanetárias que estão 
a ampliar o espaço vital do homem.

(LEMOS, 2006, p. 10).

Por último, Lemos menciona a categoria patrimonial presente neste trabalho, a qual engloba:

[...] toda a sorte de coisas, objetos, artefatos e construções obtidas a partir do meio ambiente e do saber fazer. Aliás, a palavra artefato talvez devesse ser a única a ser empregada no caso, tanto designando um machado de pedra polida como um foguete interplanetário ou uma igreja ou a própria cidade em volta dessa igreja. (LEMOS, 2006, p. 10).

A Arqueologia evidencia e estuda a materialidade das vivências humanas que, devido à sua representatividade, compõem os elementos patrimoniais de diferentes contextos. Nos últimos dois séculos, a ciência arqueológica assumiu parte do papel de recolher, identificar e analisar os vestígios de povos pretéritos para dá-los a conhecer de forma mais abrangente.

O projeto "Arqueólogo por um dia: história e natureza" executa suas ações, a partir dos estudos relacionados à Arqueologia e a outras ciências correlacionadas, e amplia sua função social de divulgação do conhecimento científico. $\mathrm{O}$ uso da memória social a partir do Patrimônio Cultural é, e já foi corrente em outros momentos e com outros objetivos. A constituição de uma perspectiva de nação atesta, desde o século XIX, as tensões políticas que transpassam o campo patrimonial. As missões artísticas e científicas patrocinadas pelo império brasileiro, princípio do campo arqueológico no país, ajudaram a cimentar tal ideário desde a independência.

Esta contextualização histórica, com os usos do patrimônio em cada tempo, é levada a termo na prática cotidiana do projeto, e nas comunicações e reflexões no âmbito da formação universitária onde acadêmicos e professores extensionistas aprofundam reflexões dessa natureza.

Ampliando as discussões e, na sequência dos conceitos relacionados à patrimonialização, torna-se necessário refletir acerca da preservação dos bens patrimoniais. Preservar não é somente guardar, compreende esta ação a atribuição de significados e a potencialização pedagógica do que se pretendente patrimonializar. Apontar para a relevância pedagógica dos bens patrimoniais não pode, entretanto, diminuir a polissemia do conjunto de evidências mobilizadas para a construção da aprendizagem.

Para os historiadores e arqueólogos, os documentos apresentam-se como meios para se entender os processos históricos. Nessa perspectiva, as evidências materiais e as fontes documentais bidimensionais, compõem o que se pode conceber como Patrimônio Histórico e Cultural. Conforme Le Goff (2003, p. 526): “O termo latino documentum, derivado de docere, 'ensinar', evoluiu para o significado de 'prova' e é amplamente usado no vocabulário legislativo". É também o historiador francês que chama a atenção para a necessidade de conceber-se documento como "produto da sociedade que o fabricou segundo as relações de força que a detinham" (LE GOFF, 2003, p. 545).

Para que a construção do conhecimento se estabeleça, portanto, é salutar que os sujeitos contemplem os espaços que compõem e identifiquem os sinais antecedentes. A partir dessa consciência não se aprende apenas um tempo que já não é; outrossim, elabora-se uma nova compreensão do contexto que o envolve e planejam-se ações enquanto agente social para exercer na plenitude os preceitos da cidadania.

Para Leff (2002), as práticas produtivas, geram formas de percepções e técnicas específicas de apropriação social da natureza e das transformações do meio. Estas relações de apropriações e transformações dependem do ambiente e das diferentes estruturas sociais e culturais.

Neste sentido, a compreensão histórica e o exercício pleno da cidadania consideram a ruptura com ideias antropocêntricas gestadas na modernidade. O conceito de Patrimônio Histórico e Cultural eleito para nortear as ações pedagógicas, ultrapassa esta visão e considera a vinculação intrínseca entre homem e natureza. Para isso, é fundamental estar atento às relações que existem entre o ambiente, o saber e o artefato; entre o artefato e o homem; entre o homem e a natureza (LEMOS, 2006, p. 9). 
A abordagem, portanto, acentua a interdisciplinaridade dos saberes, e rompe com a pseudodicotomia moderna que opunha homem e natureza. $\mathrm{O}$ ambiente, a partir desta concepção, é parte do conjunto das relações sociais e culturais dos sujeitos.

\section{Educação Patrimonial}

Partindo da concepção patrimonial que foi definida, é possível propor exercícios didáticopedagógicos a partir de qualquer contexto patrimonializado. $\mathrm{O}$ que, a priori, apresenta-se como método é antes um conceito, pois é elaborado a partir de reflexões precedentes. Não é possível, contudo, fazer definições arbitrárias, pois a inserção de um ou mais elementos na categoria patrimonial demanda reflexões profundas e disposição para reconsiderações a todo o tempo.

A Educação Patrimonial concebida no projeto é definida como "[...] um processo permanente e sistemático de trabalho educacional centrado no Patrimônio Cultural como fonte primária de conhecimento e enriquecimento individual e coletivo" (HORTA; GRUNBERG; MONTEIRO, 1999, p. 6). E, nas ações, o patrimônio arqueológico é o ponto de partida para as abordagens sobre o estudo do período pré-colonial com ênfase nas pesquisas locais.

A compreensão da relação diferenciada dos grupos humanos com o local onde se aprende e se ensina na contemporaneidade é uma convenção temporal. Essa percepção permeia, inclusive, o local onde o educandário que recebe o projeto está edificado. A problematização dessas relações, aparentemente simples, desperta cogitações que convergem para considerações que dizem respeito ao conceito de cultura. Parte-se da dinamicidade que atravessa a concepção do que seja cultura, encaminham-se reflexões que trazem à tona o entendimento de que os grupos humanos produzem cultura e expressam o mundo a partir de todos os elementos que a constituem. Para que tais elucubrações produzam efeito pedagógico no âmbito do projeto considera-se que a cultura é
[...] um processo eminentemente dinâmico, transmitido de geração em geração, que se aprende com os ancestrais e se cria e recria no cotidiano presente, na solução dos pequenos e grandes problemas que cada sociedade ou indivíduo enfrentam. (HORTA; GRUNBERG; MONTEIRO, 1999, p. 5).

A Educação Patrimonial, portanto, é concebida pela dinamicidade do conceito de cultura. Para haver Educação Patrimonial, é necessário identificar elementos que aproximem o objeto/ patrimônio do sujeito/estudante. No âmbito do projeto em desenvolvimento e de sua mobilização no contexto escolar, objetiva-se extrapolar a percepção autocentrada da atribuição de significado ao patrimônio.

O Patrimônio Histórico e Cultural e a Educação Patrimonial, por conseguinte, vão além de legitimar uma identidade. $\mathrm{O}$ patrimônio, em suas múltiplas formas, figura como um suporte de informação a ser lido e interpretado. A leitura e a interpretação, em contexto, das manifestações culturais tornadas patrimônio, testemunham as formas como diferentes grupos humanos interagem entre si e com o ambiente ao longo do tempo.

Para Pacheco (2010), a Educação Patrimonial é uma proposta interdisciplinar de ensino, que tem como tema guia o patrimônio cultural. Utilizam-se os lugares e a memória para sensibilizar os estudantes e as comunidades para a significação e a importância da conservação de bens culturais. É a sensibilidade que permite relações de pertencimento para com o patrimônio. Bem como o exercício de cidadania.

O projeto "Arqueólogo por um dia: história e natureza" busca promover uma reflexão acerca das possibilidades pedagógicas no âmbito da Educação Patrimonial, concebida como

[...] um instrumento de "alfabetização cultural" que possibilita ao indivíduo fazer a leitura do mundo que o rodeia, levando-o à compreensão do universo sociocultural e da trajetória históricotemporal em que está inserido. Este processo leva ao reforço da auto-estima [sic] dos indivíduos e comunidades e à valorização da cultura brasileira, 
compreendida como múltipla e plural. (HORTA, GRUNBERG; MONTEIRO 1999, p. 5).

A partir dos conceitos abordados até aqui, o projeto procura em cada objeto ou evidência da cultura estudar a multiplicidade de aspectos e significados. Tais abordagens são articuladas com o que propõe a Base Nacional Comum Curricular que passa a permear o currículo da Educação Básica no Brasil.

\section{A pesquisa e a extensão}

As primeiras atividades arqueológicas na região do Vale do Taquari iniciaram na década de 1960. Naquela ocasião, arqueólogos vinculados a outras instituições realizaram prospecções nas áreas abordadas. Somente no ano de 2000 - com a criação do curso de História na Univates, sendo criado, em seguida, o Laboratório de Arqueologia, vinculado ao Museu de Ciências da instituição - as pesquisas arqueológicas foram intensificadas (SCHNEIDER et al., 2017).

Com a instalação do Laboratório de Arqueologia, as intervenções identificaram áreas com vestígios de grupos populacionais de caçadores e coletores, Jê Meridionais e Guarani. Foi possível prospectar, também, sítios arqueológicos históricos decorrentes das migrações europeias dos séculos XVIII e XIX. A partir deste período, na região, ocorreu a inserção de populações de outros contextos como açorianos, africanos, alemães e italianos (Tabela 1).

Tabela 1: Sítios Arqueológicos cadastrados na região do Vale do Taquari, Rio Grande do Sul.

\begin{tabular}{|c|c|c|c|c|}
\hline RS & Sítio & Município & Data de cadastro & Etnia associada \\
\hline RS-T-100 & São Valentim & Ilópolis & $18 / 03 / 2002$ & Jê Meridional \\
\hline RS-T-101 & Tamanduá & Marques de Souza & $15 / 10 / 2001$ & Guarani \\
\hline RS-T-102 & Univates & Lajeado & $02 / 04 / 2002$ & Guarani \\
\hline RS-T-103 & Picada Augusta & Cruzeiro do Sul & $19 / 03 / 2002$ & Histórico \\
\hline RS-T-105 & Breno Wilhrich & Colinas & $19 / 03 / 2002$ & Guarani \\
\hline RS-T-107 & Adanásio Fucks & Lajeado & $12 / 08 / 2002$ & Guarani \\
\hline RS-T-108 & Sílvio Lagemann & Colinas & $12 / 08 / 2002$ & Guarani \\
\hline RS-T-109 & Augusto Beno Klein & Santa Clara do Sul & $03 / 04 / 2003$ & Histórico \\
\hline RS-T-110 & Tamanduá II & Marques de Souza & $03 / 04 / 2003$ & Guarani \\
\hline RS-T-111 & Márcio Caye & Paverama & $16 / 10 / 2003$ & Histórico \\
\hline RS-T-112 & Valmir Peters & Teutônia & $09 / 11 / 2004$ & Histórico \\
\hline RS-T-113 & João Werner Graff & Arroio do Meio & $09 / 11 / 2004$ & Guarani \\
\hline RS-T-114 & Waldemar Mertz & Marques de Souza & $09 / 11 / 2004$ & Guarani \\
\hline RS-T-116 & Celito Hergemöller & Teutônia & $26 / 06 / 2007$ & Guarani \\
\hline RS-T-117 & Décio Antônio Guerini & Cruzeiro do Sul & $25 / 10 / 2007$ & Guarani \\
\hline RS-T-119 & Colinas & Colinas & $14 / 04 / 2009$ & Guarani \\
\hline RS-T-120 & Fazenda Pedreira & Bom Retiro do Sul & $04 / 06 / 2010$ & Histórico \\
\hline RS-T-121 & Olides Bortoncello & Coqueiro Baixo & $16 / 04 / 2012$ & Caçador Coletor \\
\hline RS-T-122 & Ireno Dahmer & Marques de Souza & $04 / 01 / 2012$ & Guarani \\
\hline RS-T-123 & Deolino Morreto & Arvorezinha & $27 / 08 / 2012$ & Jê Meridional \\
\hline RS-T-124 & Narciso Belotti & Muçum & $30 / 08 / 2013$ & Guarani \\
\hline RS-T-125 & Alcir Zanella & Arvorezinha & $30 / 08 / 2013$ & Jê Meridional \\
\hline RS-T-126 & Eroni Paludo & Arvorezinha & $30 / 08 / 2013$ & Jê Meridional \\
\hline RS-T-127 & Jenucir da Silva & Soledade & $05 / 09 / 2014$ & Jê Meridional \\
\hline RS-T-128 & Costa do Forqueta & Fontoura Xavier & $05 / 09 / 2014$ & Jê Meridional \\
\hline RS-T-129 & Neuri Matiello & Ilópolis & $10 / 12 / 2014$ & Jê Meridional \\
\hline RS-T-130 & Dorildes Guarda de Paula & Arvorezinha & $20 / 11 / 2015$ & Jê Meridional \\
\hline RS-T-131 & Fazenda Espanhola & Bom Retiro do Sul & $19 / 12 / 2016$ & Histórico \\
\hline RS-T-132 & Sítio Garcia & Pouso Novo & $28 / 02 / 2018$ & Guarani \\
\hline RS-T-133 & Sítio Mattos & Cruzeiro do Sul & $28 / 02 / 2018$ & Guarani \\
\hline
\end{tabular}

Fonte: Catálogo de Sítios Arqueológicos do Laboratório de Arqueologia da Univates (2019). 
Ao longo dessas quase duas décadas, os resultados das pesquisas foram divulgados por meio de várias ações e publicações científicas, como teses, dissertações, artigos, livros e monografias (SCHNEIDER et al., 2017).

As pesquisas demonstram que a região, toponimicamente denominada Vale do Taquari na contemporaneidade, foi intensamente povoada em tempos pretéritos. O registro dos sítios arqueológicos e as atividades de escavação geram uma gama de dados, que atestam a ocupação perene da região.

Tem-se, dessa forma, a difusão do conhecimento no meio científico e a inserção da arqueologia regional no cenário de estudos sobre o período pré-colonial e pós-colonial brasileiro. As informações alcançadas com as metodologias próprias da ciência arqueológica são divulgadas em ações para a comunidade regional, seja em forma de palestras, oficina, visitas guiadas ao Laboratório de Arqueologia e, principalmente, por meio do Projeto de Extensão "Arqueólogo por um dia: história e natureza".

A Tabela 2 apresenta, quantitativamente, as atividades realizadas no âmbito do referido projeto, desde a sua gênese.

Tabela 2: Número de atendimentos do projeto "Arqueólogo por um dia: história e natureza".

\begin{tabular}{cccc}
\hline Ano & Municípios & Escolas & Alunos \\
\hline $2000-2005$ & 11 & 16 & 635 \\
\hline 2006 & 8 & 15 & 534 \\
\hline 2007 & 7 & 21 & 751 \\
\hline 2008 & 10 & 23 & 630 \\
\hline 2009 & 11 & 19 & 511 \\
\hline 2010 & 12 & 20 & 736 \\
\hline 2011 & 13 & 22 & 608 \\
\hline 2012 & 12 & 16 & 412 \\
\hline 2013 & 10 & 15 & 422 \\
\hline 2014 & 14 & 19 & 490 \\
\hline 2015 & & & \\
\hline 2016 & & & \\
\hline 2017 & & 12 & 319 \\
\hline 2018 & & 14 &
\end{tabular}

Fonte: Adaptado de Relly, Ávila e Machado (2008).

Os atendimentos registrados na Tabela 2 acontecem nas instituições de Educação Básica. Há, entretanto, um conjunto de atividades oferecidas pelo Museu de Ciências da Univates no qual o projeto também se envolve. Trata-se do Projeto "Naturalista por um dia" que acontece no campus, no Museu e em salas adjacentes. Neste conjunto de atividades interdisciplinares, o projeto oferece uma oficina intitulada "Entre vasos e pontas", antecedida por discussões atinentes à ocupação antrópica da região com ênfase nas populações pré-coloniais. Evidencia-se, dessa forma, a articulação da pesquisa com a extensão, com destaque para a interseç̧ão das abordagens entre os projetos desta natureza.

A concepção de extensão que lastreia o projeto tem como fundamento as reflexões atinentes à extensão como campo de investigação acadêmica, definições neste sentido presentes nos documentos institucionais da universidade que dá suporte ao projeto, bem como a conceituação legislativa presente na Resolução $\mathrm{n}^{\circ} 7$, de 18 de dezembro de 2018, instituída pelo Conselho Nacional de Educação (CNE) (BRASIL, 2018).

No que se relaciona às reflexões emergentes na academia, têm ganhado relevo estudos que apontam a extensão como espaço de afluência de valores como a transdisciplinaridade, cujas potencialidades didático-pedagógicas são atestadas em pesquisas de áreas de investigação atinentes à educação, como História, Geografia e Ciências. Abordam-se conteúdos como: tempo, espaço, paisagem, topografia e recursos hídricos. Cada um desses campos de conhecimento colabora para a elaboração de hipóteses acerca da ocupação do espaço ao longo do tempo.

Como consequência de investigações que contemplam tais perspectivas que intercambiam preceitos da pesquisa e da extensão tem-se a ruptura com a hierarquização dos saberes e uma espécie de relação dialética e dialógica entre as instituições e sujeitos envolvidos. A partir desta perspectiva:

A extensão, nesse processo vivencial, pode ser um espaço, um tempo e um processo próprio para desenvolver o acolhimento de pessoas, de comunidades e de projetos, dando uma nova corporalidade aos grupos e sistemas sociais com o objetivo de promover uma vida que transcenda às 
situações do cotidiano. A energia que potencializa a integração entre a teoria e a prática, e a interação, entre a ciência e a vivência, pode ser experimentada através da extensão universitária. (SÍVERES, 2013, p. 33).

A relação próxima entre pesquisa $\mathrm{e}$ extensão é, para além de exigência legal, a forma de justificar socialmente uma universidade de caráter comunitário como a Universidade do Vale do Taquari que ancora institucionalmente tais ações. Coerente com a forma como essa universidade se apresenta no contexto regional:

A Univates entende por extensão o processo de relações diretas e recíprocas com a comunidade, que, na perspectiva de democratizar o conhecimento produzido, consolida-se como um dos meios que permite a interlocução com diferentes segmentos, seja por meio de cursos, eventos, prestação de serviços, como também projetos vinculados ou não a programas de extensão, que abranjam as áreas de conhecimento em que há cursos de graduação. (UNIVATES, 2018, p. 32).

Portanto, uma concepção na qual há sinais de hierarquização dos saberes. Gradativamente, fóruns e reflexões são proporcionados a fim de ajustar o foco no sentido de tornar mais horizontal e dialógica a prática extensionista.

Entende-se que a extensão universitária estabelece fluxo de saberes sistematizados de natureza acadêmica e popular, em que a comunidade, os estudantes e professores aprendem e se retroalimentam a partir dessa troca. Nesse processo, ocorre o tensionamento dos saberes advindos do contexto acadêmico por meio da aproximação com o mundo da comunidade, o que possibilita a ressignificação do conhecimento.

Por fim as práticas extensionistas levadas a termo no projeto não ignoram o que prescreve $\mathrm{o}$ art. $3^{\circ}$ da Resolução $n^{\circ} 7$ do CNE:

A Extensão na Educação Superior Brasileira é a atividade que se integra à matriz curricular e à organização da pesquisa, constituindo-se em processo interdisciplinar, político educacional, cultural, científico, tecnológico, que promove a interação transformadora entre as instituições de ensino superior e os outros setores da sociedade, por meio da produção e da aplicação do conhecimento, em articulação permanente com o ensino e a pesquisa (BRASIL, 2018).

Considerando as reflexões acadêmicas, a partir das quais se erigem os conceitos antes apresentados e as regulamentações que emergem das instâncias oficiais, tem-se a operacionalização do conjunto de atividades desenvolvidas e constantemente adaptadas ao longo dos anos de atuação do projeto.

\section{A ação na prática}

O ensino de História na Educação Básica apresenta demandas específicas. As práticas pedagógicas pensadas no âmbito do Projeto de Extensão "Arqueólogo por um dia: história e natureza" oferecem alternativas didáticopedagógicas a partir das necessidades das escolas e dos professores parceiros.

Como já mencionado, as práticas de Educação Patrimonial são realizadas há quase 20 anos pela Univates, por meio das ações. Os resultados das pesquisas e as reflexões pedagógicas fazem parte do que se desenvolve no Laboratório de Arqueologia do Museu de Ciências dessa instituição. Parte-se da realidade do contexto escolar e dos resultados científicos, para fomentar um diálogo que propicie a formação dos estudantes e professores da escola, além de complementar a formação acadêmica dos bolsistas extensionistas. Estes elementos são analisados para o desenvolvimento de ações que contribuam para a consolidação de agentes sociais conscientes e inseridos nos espaços concebidos a partir da tridimensionalidade do tempo.

As atividades desenvolvidas no referido projeto podem ser estruturalmente definidas. Partese da capacitação dos bolsistas, instrumentalizandoos no sentido de relacionarem os conceitos estruturantes do campo científico com as práticas pedagógicas no âmbito escolar. Em seguida, 
divulga-se o conjunto de atividades junto às escolas de Educação Básica. A partir da demanda manifestada pelos professores das escolas parceiras, têm início as ações diretas.

A primeira ação, a etapa "teórica", ocorre na parte da manhã, quando são problematizados conteúdos relacionados à Arqueologia, pré-história, sítios arqueológicos, evidências arqueológicas, bem como patrimônio histórico e cultural, dissociação homem-natureza, história regional e as referências patrimoniais locais. Percebe-se que os estudantes, em alguns casos, conhecem superficialmente alguns dos assuntos que são tratados nessa etapa. As atividades ensejam a articulação dos saberes prévios com novas abordagens a partir de uma perspectiva regional.

Entre os objetivos dessa seção menos prática, está a desmistificação da profissão do arqueólogo, a apresentação das técnicas e das metodologias empregadas por este profissional.

Grande parte dos alunos normalmente pertence à faixa etária entre dez e 12 anos ( $6^{\circ}$ ano), ainda em contínuo processo de formação, elaboração e reelaboração de uma visão de mundo. Dessa maneira, tem-se a intenção de problematizar, além dos conceitos basilares antes definidos, concepções como a de tecnologia, evolução, migrações, práticas culturais e diversidade cultural.

A segunda etapa do projeto consiste em três atividades de cunho prático. A primeira dedica-se à confecção de vasilhas de cerâmica produzidas a partir da técnica do roletamento, corrente na literatura arqueológica acerca da cerâmica das populações horticultoras, às quais estão associados muitos dos sítios estudados pelo Laboratório de Arqueologia da Univates. Entre os objetivos dessa atividade, está a concepção de tecnologia empregada na resolução de problemas cotidianos a partir do que o meio oferece.

Ao finalizar a confecção das cerâmicas, os estudantes são direcionados para a segunda atividade em uma área previamente escolhida, onde é realizada a escavação em um sítio arqueológico simulado. A escavação é precedida de prospecção simulada. Nesta atividade, os estudantes avaliam a potencialidade da área para o estabelecimento de grupos humanos além de conhecerem as coordenadas do local tomadas a partir de um equipamento de geolocalização, bem como a representação do local onde estão nas cartas topográficas as quais o Laboratório dispõe.

Antes da escavação do sítio arqueológico simulado, é demarcada uma quadrícula $\left(1 \mathrm{~m}^{2}\right)$ para cada estudante. Durante a escavação, os estudantes analisam a área demarcada e escavam em busca de fragmentos de cerâmica (não arqueológicos) previamente enterrados pela equipe do projeto. Dessa forma, põem em prática as técnicas aprendidas na oficina "teórica", escavando e armazenando de forma correta a cultura material simulada.

O sítio simulado tem como objetivo pedagógico, demonstrar como os arqueólogos lançam hipóteses sobre o cotidiano dos grupos sociais que produziram determinada Cultura Material, que na simulação está sendo encontrada.

Ao voltarem para a sala de aula, os estudantes iniciam a terceira e última atividade prática. Para isso, são divididos em grupos, dando início à reconstituição da cerâmica a partir dos fragmentos encontrados na escavação. Além das técnicas específicas, esta atividade agrega pedagogicamente valores como o trabalho em equipe.

Ao finalizar as atividades práticas, os alunos elaboram um relatório de campo que contempla todas as ações realizadas durante o dia. Este instrumento auxilia a equipe de extensão a avaliar a percepção dos estudantes acerca do conjunto de atividades desenvolvidas. Percebe-se, através da análise dos relatórios de campo, que conceitos são revisitados pelos estudantes, principalmente referentes ao património histórico e cultural e a dissociabilidade entre homem e natureza. $\mathrm{O}$ conjunto de dados aludidos nos relatórios está em fase de análise e aproximação com conceitos específicos da área da educação, que potencializam a abordagem qualitativa dos documentos produzidos.

\section{Considerações finais}

A integração entre instituições, abordagens e sujeitos específicos no âmbito da produção, divulgação e significação do conhecimento 
cientificamente produzido justifica os esforços empreendidos de parte a parte. Ações como o "Arqueólogo por um dia: história e natureza" convergem para consolidar o caráter comunitário de uma instituição que juridicamente já é definida desta forma.

$\mathrm{O}$ conjunto de atividades que são apresentadas ao longo desta produção insere-se no contexto da Educação Básica, conjugando esforços, a partir da extensão universitária, com o intuito de qualificar a formação acadêmica dos estudantes envolvidos eintercambiar saberes com os professores e estudantes dos Ensinos Fundamental e Médio. As propostas tratam didaticamente os resultados das pesquisas regionalmente desenvolvidas, integrando os dados regionais a contextos mais amplos presentes nas matrizes curriculares pensadas desde as instâncias normativas da Educação Básica no país.

As interpretações dos elementos acrescentados nas produções da Arqueologia a partir de experiências palpáveis do contexto regional funcionam como gatilho para reflexões profundas em relação à ocupação humana e à integração homem e natureza. Abordagens desta ordem mobilizam professores do Ensino Fundamental e Médio no sentido de tornar pedagogicamente potente as experiências no âmbito da escola.

No que tange à formação universitária, promover o contato dos acadêmicos com contextos que, de alguma forma, permeiam o cotidiano profissional da carreira escolhida, tende a consolidar os conhecimentos mobilizados da perspectiva da qualificação profissional e pessoal. Dessa maneira, alarga-se o espaço da experiência formativa. A sala de aula da universidade, o laboratório onde as atividades são planejadas e as escolas onde se interage com os diferentes atores da comunidade são espaços de experiências que potencializam aprendizagens.

Ao sair do espaço físico da universidade e inserir-se em outro ambiente, sem perder de vista a condição de apresentar-se para a comunidade como um universitário, o acadêmico tem a oportunidade de mensurar a sua responsabilidade social enquanto estudante do Ensino Superior. É também em oportunidades como as que se apresentam que fica evidente a não hierarquização dos saberes. Nas atividades, para além da universidade e suas adjacências, enseja-se a percepção de que há saberes e possibilidades de aprendizagem em todos os espaços.

No que concerne aos impactos sociais para além dos ambientes formais de ensinoaprendizagem, é possível perceber que a aplicação deste projeto, ao longo dos anos, principalmente na região geopolítica do Vale do Taquari, tem demonstrado uma mudança na forma de ver e pensar a ocupação do espaço. Esta mudança é percebida não só na escola, visto que os professores, por já terem recebido o projeto, incorporam as informações apreendidas em suas práticas pedagógicas.

Detecta-se, ainda, a gradativa alteração na percepção da comunidade em relação aos temas referentes à história regional. Tal alteração vem à tona nos meios de comunicação social, por meio de reportagens e publicações em redes sociais. As informações abordadas nesses meios denotam a influência da divulgação dos dados científicos pedagogicamente tratados ao longo das atividades desenvolvidas.

Se, antes das pesquisas acadêmicas, a história regional começava com a chegada dos imigrantes alemães e italianos, atualmente nota-se que a linha do tempo expandiu incorporando outros grupos e cenários. A presença indígena pré-colonial e de africanos passa a ser contada, questionada e entendida de forma contextualizada, bem como as migrações recentes.

Além dos benefícios para a formação integral dos bolsistas e das novas percepções da comunidade sobre história regional, as escolas, enquanto parceiras, qualificam os currículos com abordagens regionalizadas aos conteúdos que são institucionalmente atribuídos a elas, pela sua razão precípua de existir.

$\mathrm{Da}$ perspectiva do professor, tem-se o contato com dados recentes resultantes das pesquisas realizadas no Laboratório de Arqueologia da Univates. Além disso, experienciam alternativas metodológicas para abordagem aos conteúdos 
constantes da matriz curricular da escola em que está vinculado.

Conforme mencionado, as atividades do projeto são apresentadas aos estudantes como uma proposta interativa de abordagem aos conteúdos que lhes compete estudar. Nesse sentido, percebese que a ação marca o estudante. Isso pode ser averiguado por conta da longa duração do projeto. Os retornos se dão em etapas posteriores de sua formação geral, impactando inclusive a opção em relação às escolhas profissionais e acadêmicas.

Desde sua constituição, o "Arqueólogo por um dia: história e natureza" atendeu 6.048 estudantes das escolas de Educação Básica. Entretanto, as ações de Educação Patrimonial superam essa cifra, tendo em vista que, conforme informado ao longo desta produção, abordagens com tais motivações se efetivam concomitantemente à estruturação do Laboratório de Arqueologia da Univates. O projeto permanece ativo recebendo avaliações constantes no âmbito das instâncias da instituição que o sustenta. Demonstra-se, ainda, como uma das possibilidades de curricularização da Extensão Universitária regulamentada pelas instâncias governamentais a partir de legislações específicas.

Como se pode perceber, há motivações e objetivos diferentes que, entretanto, convergem para propósitos afins. A mobilização entre as oficinas teóricas e práticas aproxima o estudante da discussão da relação entre homem e ambiente. Compreender que as transformações ambientais estão umbilicalmente ligadas às estruturas sociais e culturais oportuniza a percepção de quem se é e quais as consequências das decisões tomadas conjunturalmente. A apreensão de alguns conceitos atinentes às ciências humanas e ambientais, a partir da concretude do ambiente onde as experiências pedagógicas ocorrem, consolida a Educação Patrimonial como um vetor para a prática cidadã que tem no horizonte uma educação que enseja a autonomia dos sujeitos.

\section{Referências}

BRASIL. Constituição Federal, art. 216. 1988. Disponível em: http://portal.iphan.gov.br/uploads/ legislacao/constituicao_federal_art_216.pdf Acesso em: 7 fev. 2019.

BRASIL. Decreto $\mathbf{n}^{\circ} 25$, de 30 de novembro de 1937. Organiza a proteção do patrimônio histórico e artístico nacional. Disponível em: http://www. planalto.gov.br/ccivil_03/decreto-lei/del0025.htm. Acesso em: 7 fev. 2019.

BRASIL. Conselho Nacional de Educação. Resolução no 7, de 18 de dezembro de 2018. Estabelece as Diretrizes para a Extensão na Educação Superior Brasileira e regimenta o disposto na Meta 12.7 da Lei $\mathrm{n}^{\circ} 13.005 / 2014$, que aprova o Plano Nacional de Educação - PNE 2014-2024 e dá outras providências. Disponível em: http://www.in.gov. br/materia/-/asset_publisher/Kujrw0TZC2Mb/ content/id/55877808. Acesso em: 16 maio 2019.

HORTA, Maria de L. P.; GRUNBERG, Evelina; MONTEIRO, Adriane Q. Guia básico de educação patrimonial. Brasília: IPHAN, Museu Imperial, 1999.

IPHAN. Portaria $\mathbf{n}^{\circ}$ 07, de 01 de dezembro de 1988. Disponível em: http://portal.iphan.gov.br/ uploads/legislacao/Portaria_n_007_de_1_de_ dezembro_de_1988.pdf. Acesso em: 1 fev. 2019.

IPHAN. Portaria n 375, de 19 de setembro de 2018. Disponível em: http://portal.iphan.gov.br/uploads/ legislacao/portaria3752018sei_iphan0732090.pdf. Acesso em: 5 fev. 2019.

LEFF, Enrique; VIEIRA, Paulo Freire. Epistemologia ambiental. $3^{\text {a }}$ ed. São Paulo: Cortez, 2002.

LE GOFF, Jacques. História e memória. Campinas: UNICAMP, 2003.

LEMOS, Carlos A. C. O que é Patrimônio Histórico. São Paulo: Brasiliense, 2006.

PACHECO, I. A. Arqueologia e Patrimônio: contribuições para uma educação ambiental/ patrimonial em Mato Grosso do Sul. Orientador: Profa. Dra. Icléia Alburquerque de Vargas. Dissertação (Mestrado Profissional em Ensino de 
Ciências) - Programa de Pós-Graduação em Ensino de Ciências, Universidade Federal de Mato Grosso do Sul, Campo Grande, 2010. 134 fls.

UNIVATES. Projeto Pedagógico Institucional (PPI). Universidade do Vale do Taquari. Lajeado/ RS: Univates, 2018.

RELLY, Eduardo; DE ÁVILA, Antônio Marcos; MACHADO, Neli Teresinha Galarce. Experiências de uma Educação Patrimonial: Arqueólogo Por Um dia no Vale do Taquari-Rio Grande do Sul. Revista Cadernos do Ceom, v. 21, n. 28, p. 167-190, 2008.
SCHNEIDER, Fernanda; KREUTZ, Marcos Rogério; MACHADO, Neli Teresinha Galarce; WOLF, Sidnei. Investigações arqueológicas no Vale do Taquari, Rio Grande do Sul, Brasil. Clio - Série Arqueológica, v. 32, p. 139-186, 2017.

SÍVERES, Luiz. Princípios Estruturantes da Extensão Universitária. In: MENEZES, Ana Luisa Teixeira de; SÍVERES, Luiz (Org.). Transcendendo Fronteiras: A Contribuição da Extensão das Instituições Comunitárias de Ensino Superior (ICES). Santa Cruz do Sul: Edunisc, 2013. p. 24-48. 